\title{
Detecção de Toxoplasma gondii no sêmen de ovinos naturalmente infectados ${ }^{1}$
}

\author{
Érica P.B.X. Moraes², Eduardo B. Faria², André M. Batista ${ }^{2}$, Antonio \\ Carlos Freitas ${ }^{3}$, Jean Carlos R. Silva ${ }^{2}$, Pedro Paulo F. Albuquerque ${ }^{2}$ \\ e Rinaldo A. Mota $^{2 *}$
}

\begin{abstract}
Moraes E.P.B.X., Faria E.B., Batista A.M., Freitas A.C., Silva J.C.R., Albuquerque P.P.F. \& Mota R.A. 2010. [Toxoplasma gondii detection in the semen of naturally infected sheep.] Detecção de Toxoplasma gondii no sêmen de ovinos naturalmente infectados. Pesquisa Veterinária Brasileira 30(11):915-917. Laboratório de Doenças Infecto-Contagiosas dos Animais Domésticos, Departamento de Medicina Veterinária, Universidade Federal Rural de Pernambuco, Rua Dom Manoel de Medeiros s/ n, Dois Irmãos, Recife, PE 52171-900, Brazil. E-mail: rinaldo.mota@ hotmail.com

The aim of this paper was to study the Toxoplasma gondii shedding in the semen of naturally infected rams. Sixty-five rams were initially submitted to anti- $T$. gondii antibody detection by indirect immunofluorescence (IIF). Serologically positive rams were then submitted to semen collection for $T$. gondii DNA detection. In the serology, 6/65 (9.2\%) rams were positive, while in the nested PCR of semen there were $4 / 6(66.6 \%)$ positive rams. It can be concluded that detection of the proliferative form of $T$. gondii in semen of naturally infected rams by the nested PCR technique reinforces the need to investigate possible horizontal transmission of this parasite via semen in sheep.
\end{abstract}

INDEX TERMS: Toxoplasmosis, sheep, semen, nested PCR, transmission.

RESUMO.- O objetivo deste trabalho foi estudar a eliminação de Toxoplasma gondii no sêmen de carneiros naturalmente infectados. Foram utilizados 65 reprodutores submetidos inicialmente à pesquisa de anticorpos anti- $T$. gondii por meio da técnica de imunofluorescência indireta (IFI). Os carneiros sorologicamente positivos foram submetidos à colheita de sêmen para detecção do DNA de $T$. gondii. $\mathrm{Na}$ sorologia observaram-se 6/65 (9,2\%) carneiros positivos, enquanto no PCR nested de sêmen 4/6 $(66,6 \%)$ carneiros foram positivos. Conclui-se que a detecção, por meio da técnica da PCR nested, da forma proliferativa de T. gondii no sêmen de carneiros naturalmente infectados, reforça a

\footnotetext{
${ }^{1}$ Recebido em 15 de março de 2010.

Aceito para publicação em 9 de julho de 2010.

Parte da Tese de Doutorado do Programa de Pós-Graduação em Ciência Veterinária, Universidade Federal Rural de Pernambuco (UFRPE), do primeiro autor.

2 Departamento de Medicina Veterinária, UFRPE, Rua Dom Manoel de Medeiros s/n, Dois Irmãos,. Recife, PE 52171-900, Brasil. *Autor para correspondência: rinaldo.mota@ hotmail.com

${ }^{3}$ Departamento de Genética, (UFRPE), Av. Prof. Moraes Rego 1235, Cidade Universitária, Recife, PE 50670-901.
}

necessidade de se pesquisar sobre a possibilidade da transmissão horizontal do parasito via sêmen na espécie ovina.

TERMOS DE INDEXAÇÃO: Toxoplasmose, sêmen, PCR nested, transmissão.

\section{INTRODUÇÃO}

Em ovinos, Toxoplasma gondii é descrito como um dos principais responsáveis por problemas reprodutivos em rebanhos no mundo. Os transtornos ocorrem quando a fêmea se infecta durante a gestação, podendo ocorrer desde reabsorções embrionárias iniciais e abortos até fetos malformados e crias debilitadas e fracas, dependendo da fase gestacional (Dubey 1986, Underwood \& Rook 1992, Weissmann 2003).

A inseminação artificial possibilita que um expressivo número de fêmeas concebam num curto intervalo de tempo. No entanto, ainda pouco se sabe sobre o risco da transmissão de agentes patogênicos pelo sêmen (congelado ou diluído a fresco) com graves repercussões na produção e comercialização desses rebanhos (Andrioli et al. 2006).

O taquizoíto de $T$. gondii já foi identificado no sêmen ovino pelo bioensaio por Spence et al. (1978), Blewett et al . 
(1982) e Teale et al. (1982). Recentemente, Lopes et al. (2009) infectaram experimentalmente carneiros e detectaram o parasito no sêmen através da PCR e imuno-histoquímica. O objetivo deste trabalho foi estudar a eliminação de T. gondii em reprodutores ovinos naturalmente infectados

\section{MATERIAL E MÉTODOS}

Foram utilizados 65 carneiros de diferentes raças e idades, procedentes de propriedades localizadas nas regiões da Zona da Mata e Agreste do Estado de Pernambuco, Nordeste do Brasil. Para a pesquisa de anticorpos anti-Toxoplama gondii no soro foi utilizada a técnica de Imunofluorescência Indireta (IFI), utilizando-se anticorpos anti-IgG-ovina conjugado ao isotiocianato fluoresceína (FITC conjugated-donkey anti-sheep IgG- whole molecular $\left.{ }^{4}\right)$. Diluições do soro na razão quatro (1:64 a 1:4096) foram testadas e reações na diluição 1:64 ou maior foram consideradas positivas (Camargo 1974).

Os animais sorologicamente positivos foram submetidos à colheita de sêmen pelo método de eletroejaculação. O sêmen foi avaliado de acordo com as características macro e microscópicas conforme o Colégio Brasileiro de Reprodução Animal (CBRA 1998).

As amostras de $1 \mathrm{~mL}$ de sêmen foram submetidas à extração de DNA com DNeasy® Blood \& Tissue Kit ${ }^{5}$, utilizando-se o protocolo do fabricante. O DNA extraído foi analisado e quantificado em gel de agarose a $0,8 \%$, com marcador de peso molecular $1 \mathrm{~Kb}$ corado com brometo de etídio, visualizado em luz ultravioleta e fotodocumentado para verificação de sua qualidade. Após as extrações dos DNAs, as reações de amplificação foram realizadas em um volume final de $12,5 \mathrm{~mL}$ contendo: $2,5 \mu \mathrm{L}$ de DNA genômico; $0,5 \mu \mathrm{L}$ de cada primer à $10 \mu \mathrm{M}$ (TOXO-C1 e TOXO- N1); $2,5 \mu \mathrm{L}$ de Água Mili-Q ultrapura e $6,25 \mu \mathrm{L}$ de PCR Master Mix ${ }^{5}$ (mistura para PCR) de acordo com o protocolo do fornecedor. O perfil térmico das etapas de reações foram feitas em um termociclador $\mathrm{MJ} \mathrm{g} \mathrm{G}^{7}$, e seguido de acordo com o protocolo descrito em Spalding et al. (2006). O produto amplificado de 197pb correspondente ao DNA de $T$. gondii foi detectado por eletroforese em gel de agarose a $2 \%$ corado com brometo de etídeo, visualizado através de luz ultravioleta e fotodocumentado.

Todas as amostras negativas e controles da PCR foram submetidos a PCR nested, utilizando-se $1 \mu \mathrm{L}$ do produto do PCR simples adicionado à mistura de reação em um volume final de $12,5 \mathrm{~mL}$ contendo $0,5 \mu \mathrm{L}$ de cada primer à $10 \mu \mathrm{M}$ (TOXO-

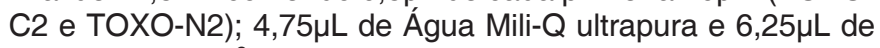
PCR Master Mix ${ }^{6}$ de acordo com o protocolo do fornecedor. O ciclo das reações foi adaptado do protocolo descrito em Spalding et al. (2006) e consistiu de uma desnaturação do DNA inicial a $95^{\circ} \mathrm{C}(4 \mathrm{~min})$ e seguida de 35 ciclos a $95^{\circ} \mathrm{C}$ por 1 minuto para a desnaturação, $62^{\circ} \mathrm{C}$ por 30 segundos para o anelamento, $72^{\circ} \mathrm{C}$ por 1 minuto para a extensão e um período de extensão final de 10 minutos a $72^{\circ} \mathrm{C}$. O produto amplificado de $97 \mathrm{pb}$ referente a $T$. gondii foi detecta por eletroforese em

\footnotetext{
${ }^{4}$ FITC conjugated-donkey anti-sheep IgG- whole molecular, SIGMAAldrich, PO Box 14508, St Louis, Missouri, USA.

${ }^{5}$ DNeasy® Blood \& Tissue Kit, QIAGEN GmbH, Strasse 1, 40720 Hilden, Germany.

${ }^{6}$ PCR Master Mix, Promega, 2800 Woods Hollow Road, Madison, Wisconsin, USA.

${ }^{7}$ Peltier Thermal Cycler MJ96G, Biocycle Co. Ltd, Hangzhou, China.
}

gel de agarose a $2 \%$ corado com brometo de etídio e visualizado através de luz ultravioleta e fotodocumentados. Os dois pares de primers utilizados são derivados do gene B1 correspondentes aos nucleotídeos 694-714, 887-868, 757-776 e 853831 (Burg et al. 1989, Spalding et al. 2006).

\section{RESULTADOS}

Das 65 amostras de sangue total analisadas, $6(9,2 \%)$ foram consideradas positivas com títulos variados. Detectou-se DNA de Toxoplasma gondii em amostras seminais de $4 / 6(66,6 \%)$ dos animais reagentes na IFI. No Quadro 1 é demonstrado a correlação entre a reação sorológica e detecção no sêmen.

\section{Quadro 1. Resultados dos animais sorologicamente positivos (IFI) e detecção do DNA parasitário (PCR nested) nas amostras de sêmen total}

\begin{tabular}{|c|c|c|c|c|c|c|}
\hline Ovino/exame & 07M & $24 \mathrm{M}$ & $40 \mathrm{M}$ & $44 \mathrm{M}$ & $47 \mathrm{M}$ & $59 M$ \\
\hline $\begin{array}{l}\text { Reação sorológica } \\
\text { (IFI) }\end{array}$ & $1: 64$ & $1: 256$ & $1: 256$ & $1: 512$ & $1: 256$ & $1: 128$ \\
\hline $\begin{array}{l}\text { Detecção DNA } \\
\text { (PCR nested) }\end{array}$ & $-a$ & + & + & + & + & - \\
\hline
\end{tabular}

\section{DISCUSSÃO}

A ocorrência de formas infectantes de Toxoplasma gondii já foi anteriormente demonstrada no sêmen de humanos infectados (Martinez-Garcia et al. 1996), bovinos (Scarpelli et al. 2009), suínos (Moura et al. 2007), caninos (Arantes et al. 2009), caprinos (Dubey \& Sharma 1980) e ovinos (Spence et al. 1978, Blewett et al. 1982, Teale et al. 1982, Lopes et al. 2009), originando discussões sobre outras possíveis formas de transmissão do parasito uma vez que se desconhece a importância relativa da via venérea.

Nesse estudo observou-se que os animais com os maiores títulos de anticorpos foram aqueles que apresentaram $T$. gondii no sêmen através da PCR nested, destacando-se os títulos 256 e 512 que são relativamente baixos quando comparados àqueles relatados por Lopes et al. (2009) que trabalharam com carneiros experimentalmente infectados e observaram títulos de 4056 associado à detecção do parasita no sêmen.

A presença de patógenos no sêmen é um achado relevante, pois abre discussão sobre a possibilidade de transmissão venérea, implantando repercussão no manejo e nas biotécnicas reprodutivas atualmente aplicadas, principalmente quanto à inseminação artificial (IA) por ser cada vez mais utilizada por produtores de ovinos no Brasil (Hare 1985, Philpott 1994, Andrioli et al. 2006).

Nesse estudo não foi possível estimar a fase da infecção quando os animais iniciaram a eliminar o parasita no sêmen, pois as amostras foram obtidas em um único momento. Sabe-se que em ovinos, o primeiro relato desta eliminação, ocorreu nos dias 7, 14, 20, 25 e 32 p.i. (Spence et al. 1978). Já Teale et al. (1982) detectaram o parasita em $50 \%$ dos machos infectados apenas em duas ocasiões 16 
e 26 dias p.i. Em outro estudo realizado por Lopes et al. (2009), T. gondii foi detectado no sêmen através da bioprova e PCR em dias variados (5-70 dias p.i). Em bovinos, Scarpelli et al. (2009) também detectaram o parasita no sêmen através da bioprova a partir do dia 7 até 84 dias p.i., sendo o período mais longo já observado na infecção experimental.

Os ovinos utilizados neste estudo apresentavam-se assintomáticos no momento da coleta do sêmen. De acordo com Terpsidis et al. (2009), a infecção toxoplásmica também pode causar alterações andrológicas e reprodutivas no macho, independentemente da espécie acometida. Estes autores ao infectarem ratos Wistar comprovaram alterações nos parâmetros reprodutivos e andrológicos, principalmente em relação à motilidade, concentração e morfologia espermática. No presente estudo, apenas 12,3\% animais apresentaram o exame andrológico insatisfatório, embora ao analisar os animais infectados apenas um animal mostrou um exame andrológico reprovado. Este animal apresentou diminuição no volume do ejaculado, motilidade e vigor espermático e aumento das patologias (morfológicas) espermáticas. Contudo não se pode atribuir esse achado como consequência da infecção natural, pois alguns animais não infectados também apresentaram esse mesmo padrão espermático. Para comprovar a influência desse parasita nos achados do exame andrológico de carneiros é necessário reproduzir experimentalmente a infecção e acompanhar os animais em diferentes tempos para se concluir sobre esses parâmetros. Sobre esse aspecto, Teale et al. (1982) e Lopes et al. (2009) relataram diminuição no volume do ejaculado, da motilidade e do vigor espermático em carneiros infectados.

A detecção de formas proliferativas de $T$. gondii no sêmen de reprodutores naturalmente infectados por meio da PCR nested reforça a necessidade de intensificar os estudos sobre a possibilidade da transmissão horizontal do parasita via sêmen na espécie ovina.

Agradecimentos - Este estudo foi financiado pelo Conselho Nacional de Desenvolvimento Cientifico e Tecnológico (CNPq) sob Proc. no.472459/2008-2.

\section{REFERÊNCIAS}

Andrioli A., Gouveia A.G., Martins A.S., Pinheiro R.R. \& Santos D.O. 2006. Fatores de risco na transmissão do lentivírus caprino pelo sêmen. Pesq. Agropec. Bras. 41:1313-1319.

Arantes T.P., Lopes W.D.Z., Ferreira R.M., Pieroni J.S.P., Pinto V.M.R., Sakamoto C.A. \& Costa A.J. 2009. Toxoplasma gondii: Evidence for the transmission by sêmen in dogs. Exp. Parasitol. 123:190-194.
Blewett D.A., Teale A.J., Miller J.K., Scott G.R. \& Buxton D. 1982. Toxoplasmosis in rams: Possible significance of venereal transmission. Vet. Rec. 24:73-75.

Burg J.L., Grover C.M., Pouletty P. \& Boothoyd J.C. 1989. Direct and sensitive detection of pathogenic protozoan. Toxoplasma gondii, by polymerase chain reaction. J. Clin. Microbiol. 27:1787-1792.

Camargo M.E. 1974. Introdução às técnicas de imunofluorescência. Revta Bras. Patol. Clín. 10:143-169.

CBRA. 1998. Manual para Exame e Avaliação de Sêmen Animal. $2^{a}$ ed. Colégio Brasileiro de Reprodução Animal, Belo Horizonte. 49p.

Dubey J.P. \& Sharma S.P. 1980. Prolonged excretion of Toxoplasma gondii in semen of goats. Am. J. Vet. Res. 41:794-795.

Dubey J.P. 1986. A review of toxoplasmosis in cattle. Vet. Parasitol. 22:177-202.

Dubey J.P. 1994. Toxoplasmosis. J. Am. Vet. Med. Assoc. 205,15931598.

Hare W.C.D. 1985. Diseases transmissible by semen and embryo transfer techniques. Technical Series, Office International des Epizooties, Paris. 117p.

Lopes W.D.Z., Costa A.J., Souza F.A., Rodrigues J.D.F., Costa G.H.N., Soares V.E. \& Silva G.S. 2009. Semen variables of sheep (Ovis aries) experimentally infected with Toxoplasma gondii. Anim. Reprod. Sci. 111:312-319.

Martinez-Garcia F., Regadera J., Mayer R., Sanchez S. \& Nistal M. 1996. Protozoan infections in the male genital tract. J. Urol. 156:340349.

Moura A.B., Costa A., Jordão Filho S., Paim B.B., Pinto F.R. \& Di Mauro D.C. 2007. Toxoplasma gondii in sêmen of experimental infected swine. Pesq. Vet. Bras. 27:430-434.

Phlipott M. 1994. The dangers of disease transmission by artificial insemination and embryo transfer. Brit. Vet. J. 150:209.

Scarpelli L., Lopes W.D.Z., Migani M., Bresciani K.D.S. \& Costa A.J. 2009. Toxoplasma gondii in experimentally infected Bos taurus and Bos indicus semen and tissues. Pesq. Vet. Bras. 29:59-64.

Spalding S.M., Angel S.O. \& Amendoeira M.R.R. 2006. Toxoplasmose, p.102-111. In: Rossetti M.L., Silva C.M.D. \& Rodrigues J.J.S. (Eds), Doenças Infecciosas: diagnóstico molecular. Guanabara Koogan, Rio de Janeiro.

Spence J.B., Beattie C.P., Faulkner J., Henry L. \& Watson W.A. 1978. Toxoplasma gondii in the semen of rams. Vet. Rec. 14:38-39.

Teale A.J., Blewett D.A., Miller J.K. \& Buxton D. 1982. Experimentally induced toxoplasmosis in young rams: The clinical syndrome and semen secretion of toxoplasma. Vet. Rec. 17:53-55.

Terpsidis K.I., Papazahariadou M.G., Taitzoglou I.A., Papaioannou N.G., Georgiadis M.P. \& Theodoridis I.T. 2009. Toxoplasma gondii: Reproductive parameters in experimentally infected male rats. Exp. Parasitol. 121:238-241.

Underwood W.J. \& Rook J.S. 1992. Toxoplasmosis infection in sheep. Compend. Contin. Educ. Pract. Vet. 14:1543-1549.

Weissmann J. 2003. Presumptive Toxoplasma gondii abortion in a sheep. Can. Vet. J. 44:322-324. 